\title{
re \\ REVISTT \\ ENTRERIOS \\ O GPS perde pra mim longe! Cartopráticas e políticas caiçaras em navegação no mar de dentro
}

\author{
Karina da Silva Coelho \\ Doutoranda em Antropologia Social na Universidade de São Paulo \\ kasilvacoelho@gmail.com
}

Resumo: Caiçaras e pescadores artesanais da região do Lagamar (na divisa entre o litoral paulista e paranaense) agenciam conhecimentos e percepções muito refinados para se orientarem no mar durante a navegação. Neste artigo descreverei as formulações de alguns interlocutores sobre as práticas de marcar pontos e reconhecer poitadas ou pesqueiros no mar de dentro. Quando me explicam sobre o uso dessas técnicas para mapear ou marcar lugares bons para pesca, eles sempre enfatizam sua precisão, pois o acúmulo desses conhecimentos capacita o pescador a se orientar de maneira muito mais precisa que um GPS. Navegar e se localizar por um território em constante movimento demanda aprender a lidar com a instabilidade do mar e da terra, pois a movimentação das marés e dos ventos e as combinações entre eles produzem distintas configurações geoespaciais em diferentes escalas de tempo. Um pesqueiro ou poitada não são pontos fixos, especificação essencial para se marcarem coordenadas num GPS. Nesse sentido, proponho uma reflexão sobre as técnicas, conhecimentos e politicas caiçaras como "cartopráticas", pautadas nas experiências e associadas às práticas dos lugares, suas histórias e nos acontecimentos geológicos e cosmológicos que atravessam o território. Interessa refletir sobre a articulação política de conhecimentos que localizam pessoas, práticas e lugares de uma maneira que é inacessível à cartografia convencional; e discutir de que modo as tensões entre cartografias, conhecimentos e técnicas se relacionam com as contradições da política ambiental brasileira, demandando processos de composição e resistência no que pode ser lido como politicas de estarno mundo.

Palavras-chave: Conhecimento; Território; Movimento; Cartopráticas.

Abstract: Caiçaras and artisanal fishermen from Lagamar region (between Sao Paulo and Paraná coast) assembly complex knowledges and perceptions to navigate. In this article I intend to describe some formulations about the practices of marking points and recognizing poitadas in the inner sea. When they teach me about the usage of these techniques, they always emphasize its accuracy, because the accumulation of these knowledges enables the fisherman to navigate much more accurately than a GPS. To navigate and locate around a territory in constant movement is necessary to learn how to deal with sea and land instabilities, because the tidals and winds movements and the combination between them produce differents geospatial configurations in differents timescales. Fishing spots or poitadas are not fixed points, hence lack a essential requirement to set GPS coordinates. I propose a reflection about caiçara's techniques, knowledges and policies like "cartopractices", based on the experiences and attached to local practices, its histories and the geological and cosmological events passing through the territory. I' $m$ interested about the political articulation of knowledges which locates people, practices and places in a way that is inacessible to conventional cartography; discussing in which forms the strains between cartographies, knowledges and techniques are related with the contraditions of brazilian environmental policies, demanding composition and resistance processes in what can be read as politics of being in the world.

Key-words: knowledge; territory; movement; cartopractices. 


\section{Introdução}

O presente artigo tem como ponto de partida alguns conhecimentos e percepções de caiçaras $^{1}$ e pescadores artesanais para se orientarem durante a navegação no mar de dentro ${ }^{2}$. Ao concentrar-me nas narrativas que eles produzem sobre suas habilidades em marcar pontos ${ }^{3} \mathrm{e}$ reconhecer poitadas ou pesqueiros, descrevo algumas de suas reflexões sobre a precisão das técnicas que utilizam para se orientarem e se localizarem no mar em relação ao uso de aparelhos GPS (sistema de posicionamento global), por pescadores amadores e barqueiros que não transitam na região do Lagamar com frequência. Esse território marítimo e terrestre é atravessado por fluxos de movimentos (marés, ventos, pessoas, animais marinhos e terrestres) que produzem acontecimentos em seus encontros. O movimento do mar através dos ciclos dos ventos e dos regimes de marés, cobre e descobre periodicamente praias continentais e insulares, coroas, bancos de areia e manguezais, e viver nesses ambientes móveis e dinâmicos requer dos caiçaras e pescadores artesanais o agenciamento de um conhecimento muito complexo e refinado, baseado na constante observação e experimentação.

Esses conhecimentos se baseiam nas suas constantes andanças pelo território. Para percorrer a região é preciso saber-andar por terra e saber-navegar pelo mar, conhecimentos adquiridos e atualizados através dos seus movimentos por entre vilas insulares e continentais na divisa entre os municípios de Guaraqueçaba, no Paraná, e Cananéia, em São Paulo. Essa região faz parte do Lagamar, um complexo estuarino-lagunar que se estende desde os municípios litorâneos paulistas de Iguape e Cananeia até os municípios de Guaraqueçaba e Paranaguá, no Paraná. O Lagamar é território de caiçaras e pescadores artesanais, mbya guarani e quilombolas, povos que possuem um manejo muito específico desses lugares, pautado pelos seus modos de vida e suas relações com seres não-humanos que também habitam esses lugares e possuem seus próprios conhecimentos, movimentos e práticas.

Por estar inserido num dos maiores remanescentes contínuos de Mata Atlântica em bom estado de preservação, foram criadas nos municípios que integram o Lagamar, a partir da década de 1960, mais de $50^{4}$ Unidades de Conservação (UC) federais, estaduais e municipais, que integram o Mosaico Lagamar, que abrange, além de Iguape, Cananeia, Guaraqueçaba e Paranaguá, outros dez municípios paranaenses e nove paulistas - ocupando uma área de 1.622.168 ha ${ }^{5}$. O conceito Mosaico de Áreas Protegidas foi instituído pelo Sistema Nacional de Unidades de Conservação (SNUC) e tem como objetivo promover uma "gestão conjunta e integrada" entre as unidades de conservação abrangidas pela área, que podem estar próximas, justapostas ou sobrepostas (BRASIL, 2000).

Regidas pelo SNUC ou pelos próprios estados e municípios - no caso das UCs estaduais e municipais -, essas unidades de conservação se sobrepõem aos territórios terrestres e marítimos dos povos tradicionais que habitam essas regiões e os interditam de livremente manejar seus territórios, segundo seus modos de vida. Essas interdições impactam de maneiras distintas os povos que habitam essa região. A falta de instrumentos jurídicos que reconheçam e regularizem

1 Caiçara é um dos segmentos reconhecidos pela legislação brasileira como "povos e comunidades tradicionais". São povos que habitam um mesmo território sociocultural e ambiental que se estende entre o litoral sul do estado do Rio de Janeiro até o litoral sul do estado do Paraná. Toda essa região é reconhecida como um dos maiores remanescentes de Mata Atlântica em bom estado de conservação.

2 Mar de dentro é uma categoria amplamente utilizada para designar áreas do mar que se localizam entre baías, estuários e manguezais e que se conectam com o mar de fora através de barras. Essas regiões são propícias para a reprodução de inúmeras espécies endêmicas da Mata Atlântica, consideradas, portanto, como um berçário natural.

3 As categorias, conceitos e falas dos sujeitos desta pesquisa serão grafados em itálico.

4 http://www.icmbio.gov.br/portal/mosaicosecorredoresecologicos/moscaicosreconhecidos-ocialmente/1870mosaico-de-unidades-de-conservacao-donlitoral-sul-de-sao-paulo-e-do-litoraldo-parana-lagamar, visualizado em 28/10/2019.

5 Descrevo a criação de UCs na região do Lagamar no Paraná em Coelho $(2014,2016)$. 
os territórios de caiçaras e pescadores artesanais e o histórico de excessos cometidos na gestão e fiscalização pelos órgãos ambientais colaboram para criar um cenário conflituoso. Foi através desse contexto de interdições que muitas práticas tradicionais passaram a ser criminalizadas, como o cultivo de roças, determinados tipos de pesca e uso de certos apetrechos ou armadilhas em algumas regiões do mar de dentro e de fora.

A criminalização das práticas caiçaras ao longo do Lagamar revela contradições da política ambiental brasileira. Do litoral norte do Paraná ao litoral sul de São Paulo foram criadas desde a década de 1960 unidades de conservação de proteção integral, as mais restritivas, e embora apresentem diferenças significativas em suas gestões - como entre o Parque Nacional do Superagui, no Paraná, e o Parque Estadual Ilha do Cardoso, em São Paulo - possuem semelhanças entre si, principalmente pela falta de diálogo com que foram instituídas, sem considerar os conhecimentos caiçaras e os seus modos de manejar e mapear seus territórios. Em ambos os estados a criação e administração das UCs, através das fiscalizações, tem operado uma "expulsão pelo cansaço", como tão bem descreveu Adriana deSouza Lima ${ }^{6}$, presidente da União dos Moradores da Juréia, sobre o modo como os órgãos gestor e fiscalizador da Estação Ecológica Juréia-Itatins, em Iguape (SP), conduzem a administração da UC:

Acontece uma expulsão pelo cansaço porque o governo não veio e tirou cada um de uma vez, nem tirou todo mundo de uma vez só, mas foi tirando o direito de plantar, de pescar, da convivência, negou escola, tirou as estradas e caminhos. As pessoas começam a passar fome, necessidade. O Estado foi impedindo a liberdade que as comunidades tinham, foi fazendo com que nosso modo de vida deixasse de existir (Adriana de Souza Lima).

Essa frase sintetiza o sentimento de muitos moradores das vilas insulares e continentais em relação à atuação das unidades de conservação de proteção integral criadas sobre os seus territórios. Melhor seria se tivessem nascidos como mico-leão-da-cara-preta ou outro animal qualquer, disse uma professora do município de Guaraqueçaba, em uma postagem nas redes sociais ao refletir sobre as interdições colocadas pelas Unidades de Conservação que se sobrepõem aos territórios.

A grande questão em relação às interdições, segundo os moradores, é que o conhecimento que baseia essas leis não condiz com as especificidades locais. Os períodos de defeso de algumas espécies de camarão e bagre, no qual a pesca fica proibida por alguns meses do ano, são alguns exemplos. Segundo os pescadores, os períodos de defeso não coincidem com os períodos reprodutivos dessas espécies na região, ficando os pescadores proibidos de pescá-los justamente quando deveriam. A lei do defeso, como algumas outras que restringem determinados tipos de pesca ou uso de apetrechos, são as mesmas de norte a sul da costa da brasileira, muitas vezes sem considerar as especifidades regionais.

A cartografia convencional e o conhecimento acadêmico são utilizados pelos órgãos federais, estaduais e municipais no mapeamento dessas áreas e respaldam a criação de leis ambientais, em detrimento dos conhecimentos e práticas dos caiçaras e pescadores artesanais. A falta de diálogo com que esses processos são conduzidos e os conhecimentos que os baseiam entram em conflito com os modos como os habitantes dessas regiões se relacionam com o mar,

\footnotetext{
6 Extraída da matéria: “Caiçaras lutam contra 'expulsão pelo cansaço' de Estação Ecológica da Juréia (SP)”, de Pedro Ribeiro Nogueira para o jornal Brasil de Fato, de 24 de junho de 2019. Disponível para visualização em: https://www.brasildefato.com.br/2019/06/24/caicaras-lutam-contra-expulsao-por-cansaco-de-estacaoecologica-da-jureia-sp/. Nessa matéria, é relatada uma ameaça de demolição de uma casa da comunidade Rio Verde-Grajaúna por funcionários da Fundação Florestal em 18 de junho de 2019.

$7 \mathrm{O}$ mico leão-da-cara-preta é uma especie endêmica da ilha do Superagui. Embora já muito conhecido pelos filhos das vilas da ilha, foi somente em 1990 que a espécie foi "encontrada" por pesquisadoras e catalogada pela primeira vez. Desde então o primata integra uma série de projetos viabilizados por ONGs ambientalistas e pelo próprio Instituto Chico Mendes de Conservação da Biodiversidade (ICMBio).
} 
os rios, a mata e os animais. Sequer faz sentido para eles uma concepção de "meio ambiente" e "conservação" compartimentada como a operada pelos órgãos ambientais - que não os inclua e que desconsidera as relações que eles mantêm com seus territórios e todos os entes que os compõem. As pessoas que habitam esse território também são parte constitutiva desse "meio ambiente" a ser preservado. É através das relações entre pescadores, peixes, marés, ventos, Pai do Mato e demais animais e entes que habitam esses territórios que se estabelecem modos de manejar apropriadamente esses territórios, de resistir neles. É na feitura cotidiana dessas relações que se estabelecem políticas de estar no e compor com o mundo.

Interessante pensar que os períodos de defeso são baseados em um pressuposto ontológico do Estado, um "ato de fé no futuro baseado no passado", como afirma Almeida (2013: 12). Pois é com base nessa fé que o Estado assegura que camarões e bagres estarão se reproduzindo neste período, uma vez que os próprios moradores discordam desta formulação. "A certeza na existência futura do peixe que será pescado é parte integrante de ontologias naturalistas" (2013:13). Os pescadores sabem muito bem que não é assim. O mar é feito de fluxos de movimentos. Não só de ventos e correntes de maré, mas também de outros fenômenos atmosféricos $^{8}$ e dos fluxos das espécies animais que por ali transitam em determinado momento das suas linhas de vida (cf. INGOLD, 2015). E eles não transitam do mesmo modo todos os anos. Tem anos em que a safra da tainha e do robalo são boas, em outros não. E isso decorre de uma série de interrelações que se dão no próprio movimento desses peixes e dos demais fatores ambientais que possibilitam que tainhas adentrem as baías da região, por exemplo.

O que os moradores contestam há muitos anos é o ato de colocar na ilegalidade práticas que sintetizam conhecimentos e relações dos moradores com a terra e o mar, responsáveis pelo bom estado de conservação da mata atlântica. Tratam-se de formas de governança do território que desconsideram o conhecimento e a relação dos moradores com os lugares em que vivem, colocando esses territórios em constante disputa (POVINELLI, 2016).

Analiso aqui algumas composições caiçaras com o seu território, em especial os modos de se orientar na navegação em mar de dentro através da criação de uma memória rápida a partir de técnicas de triangulação de pontos. Descrevo essas técnicas e conhecimentos inspirada pela ideia de "cartopráticas", definidas por Mauro Almeida (2012: 15), como conjuntos de práticas e técnicas que "localizam pessoas e atividades em ontologias espacializadas", distinguindo-se da cartografia convencional que localiza " pessoas e coisas em um espaço único e convencionalizado pela ontologia cartográfica onde escala, projeções e legendas são padronizadas". Apresento os argumentos e reflexões em duas sessões, na primeira descrevo e qualifico os movimentos desses territórios compostos (entre terra e mar), e na segunda sessão argumento porque as técnicas caiçaras são mais precisas para a navegação nas baías e mares do Lagamar em relação à cartografia convencional. Retomo esses apontamentos nas considerações finais a fim de enfatizar seus conhecimentos, composições políticas e resistências.

\footnotetext{
8 Um exemplo é que neste ano (2019) o início da safra da tainha, que ocorre a partir do dia $1^{\circ}$ maio, atrasou por influência do El Niño. Os cardumes de tainha costumam migrar anualmente a partir de maio, saindo da Lagoa dos Patos, no Rio Grande do Sul, e subindo a costa brasileira. Neste ano, por influência do El Niño o inverno apresentou temperaturas amenas e chuvas intensas, motivo pelo qual as tainhas demoraram a adentrar os costões. Informações disponíveis em: https://www.nsctotal.com.br/noticias/baixa-quantidade-de-tainha-preocupa-pescadores-desanta-catarina, visualizado em 20/07/2019.
} 


\section{Territórios em movimento}

Já passamos muito medo aqui com maré alta. Isso aqui é assim, sempre crescendo e diminuindo. Ouvi frases como essa inúmeras vezes, pois caiçaras e pescadores artesanais dessas vilas compõem com um território em movimento. O fluxo das águas, através das marés e dos ventos, e a combinação desses elementos produz marés mais altas ou baixas de acordo com as fases da lua, os ventos e as estações do ano.

A maré combinada com os ventos produz efeitos no movimento do mar. E esses efeitos variam de acordo com o período do ano, produzindo ciclos sazonais na configuração desses territórios através dos movimentos dos corpos que os compõem. No inverno, por exemplo, as marés são mais altas e os ventos sopram mais forte. O movimento constante desses ambientes é entrelaçado pelas relações das famílias no território, pelo modo como vivem a vida.

A combinação entre lua cheia ou nova produz as marés de lua e durante o inverno elas são ainda mais intensas: ela enche e vaza mais, me ensinou um pescador. E esse movimento do mar, através dela, ocasiona pontos de erosão ao longo da ilha do Superagui. O mar come terra do Superagui (PR) e a leva para a ilha do Cardoso (SP), fazendo crescer a extensão dessa ilha. Esses acontecimentos produzem inúmeras mudanças na composição geográfica das vilas, e também produzem respostas e composições dos moradores, que se articulam criativamente para se manter no território?.

O constante processo erosivo nessa região demanda um conhecimento muito refinado dos movimentos do mar e dos ventos, e uma disposição a compor com um território em movimento. Compor aqui não se refere a um ato terminado, mas a um ato contínuo de composição conjunta entre humanos e não-humanos. Os caiçaras inventam formas de compor com as adversidades que lhes aparecem (interdições de uso do mar e da terra através das leis ambientais e unidades de conservação; e a própria ação do mar, que come e faz crescer terra) resistindo e adaptando-se a elas - num uso tempestivo das leis ambientais, e também se adaptando a novas configurações geoespaciais de suas vilas em função das erosões.

O encontro de uma maré de lua com determinado vento durante o inverno intensifica erosões. Nos últimos 60 anos a vila de Barra do Ararapira (localizada na Ilha do Superagui) teve cerca de 100 metros comidos pelo mar.

A natureza faz um trabalho muito dinâmico, segundo Seu Rubens Muniz, da Barra do Ararapira:

Essa erosão que vai fazendo assim, que vai comendo, vai tirando areia, ela vai fazendo um trabalho, ela vai pra outro lugar. A vazante faz uma coisa, leva, e a enchente faz outra, a maré de enchente faz outra. O vento nordeste faz um trabalho, o vento sul faz outro. É tudo isso, tem um trabalho bastante dinâmico, a natureza faz (Seu Rubens Muniz).

Ao falar sobre a recorrência do avanço do mar sobre a Barra do Ararapira, Seu Rubens me ensinou que o mar come terra do Superagui e faz crescer terra em outros lugares, a ilha do Cardoso é um deles. A maré de enchente faz um trabalho e a maré vazante faz outro, e esse movimento é impulsionado pela força de maré, a correnteza da água que entra pela barra do Ararapira. O Mar do Ararapira desemboca no oceano atlântico através da barra do Ararapira, uma desembocadura localizada no mar, entre as ilhas do Superagui e do Cardoso, sobre a qual é defi-

\footnotetext{
9 Em minha dissertação de mestrado (COELHO, 2014) foquei no modo criativo com que os moradores da região do Superagui manejavam internamente as interdições ambientais. O que chamo de "modo criativo" de manejar as interdições, muitas vezes jogando contra elas, remete a um uso tempestivo das leis ambientais. Esse manejo interno das interdições alude à maneira como Vieira $(2015,2018)$ pensa a resistência através do "agenciamento nativo da pirraça" (: 24) em sua pesquisa sobre o Quilombo da Malhada. No contexto analisado pela autora, a resistência "é agenciada como criação das possibilidades de vida" (:23).
} 
-nida a divisa entre os estados do Paraná e São Paulo. É através dessas barras (em constante movimento) que as águas do mar de dentro / rio, e do mar de fora se encontram e seguem seus fluxos, as águas do estuário em direção ao oceano e vice e versa.

Ainda que as histórias das famílias dessa região sejam atravessadas por sucessivas erosões, que demandaram a reconstrução de suas casas em lugares mais afastados do mar nessas últimas décadas, em agosto de 2018 ocorreu um acontecimento de maior impacto na configuração geoespacial das ilhas. No dia 27 de agosto, durante a lua cheia, no período de maré de lua, o movimento do mar de dentro rompeu uma estreita faixa de terra da ilha do Cardoso, fazendo com que ele se encontrasse com o mar de fora, dividindo a ilha em duas porções territoriais - e separando a vila de Pontal do Leste das outras vilas da ilha, Vila Rápida, Nova Enseada da Baleia, Marujá e Cambriu.

Essa divisão está relacionada ao movimento da barra do Ararapira, localizada a cerca de 6 quilômetros dali. O fluxo das águas, através das marés, e os ventos são responsáveis pela barra estar em constante movimento, e a combinação desses elementos produz marés mais altas ou baixas de acordo com as fases da lua, os ventos e as estações do ano. A região em que a ilha se dividiu é denominada Restinga do Cardoso ou Restinga do mar do Ararapira, uma área da ilha do Cardoso que é uma faixa estreita de areia (se comparada à área predominantemente montanhosa da ilha) com vegetação de restinga, localizada a poucos metros de distância da ilha do Superagui. Segundo moradores, essa parte da ilha do Cardoso cresceu devido ao processo de erosão da ilha do Superagui e sua posterior progradação (aumento territorial de alguma área próxima) da ilha do Cardoso ao longo dos anos, ocasionado pelo movimento da barra do Ararapira no sentido sudoeste através dos ciclos das marés e dos ventos.

A lua domina e predomina sobre o mar, e ele sobre a terra. Os atos de comer e fazer crescer descrevem processos de territorialização, desterritorialização e reterritorialização constantes, o que permite pensar que o território não existe previamente. Ele se constitui a partir de movimentos de lugares (no mar e na terra), espécies animais, pessoas e seus conhecimentos e habilidades, de modo processual e relacional. Um conhecimento que é sempre feito, sempre processo, assim como são os lugares da região, que devido às mudanças em suas configurações espaciais passam a ser denominados como velhos ou novos. Interessa pensar na produção de chaves interpretativas que permitam compreender, apreender e compor com o lugar, e que também dão sentido à vida vivida (às políticas da vida; a um posicionar-se, colocar-se no mundo). Ao descrever os modos caiçaras de habitar o território penso sobre como o movimento de todos esses agentes (pessoas, mar, ventos, terra, bichos, coisas) é o que constitui uma territorialidade pautada na experiência, percepção, engajamentos e habilidades, feitos e adquiridos em movimento.

É importante ressaltar que embora o movimento da barra, através dos ventos, marés e estações do ano, tenha sido um elemento fundamental para a abertura de uma nova barra e a consequente divisão física da ilha, a ação humana tem intensificado esse processo, como é possível ver através do "acidente" ocorrido com o Catamarã Maratayama, pertencente à prefeitura de Ilha Comprida, embarcação que faz passeios turísticos na região do Lagamar paulista e paranaense.

\footnotetext{
10 Neste artigo menciono duas barras do Ararapira. Uma barra geológica, localizada no mar, cujo movimento define e impacta as vidas dos moradores das vilas das ilhas do Superagui e do Cardoso, e Barra do Ararapira, vila cujo nome é definido pela proximidade com a barra geológica. Quando me referir à formação geológica, $\underline{\text { barra será }}$ grafado com $\underline{\mathbf{b}}$ minúsculo; quando me referir à vila, $\underline{B}$ arra será grafado com $\underline{\mathbf{B}}$ maiúsculo.
} 
Desde o início de 2015 a comunidade de Enseada da Baleia (localizada na ilha do Cardoso) vinha sentindo os impactos da passagem do Catamarã, como o aumento do processo erosivo e impactos na estabilidade de suas embarcações devido à alta velocidade dessa embarcação. Em 07 de fevereiro de 2015, o Catamarã, sem autorização prévia da comunidade, realizou inúmeras tentativas de atracar na vila em um local de forte correnteza. As manobras utilizadas pelo piloto acionaram uma alta potência da embarcação e provocou "o deslocamento imediato de 20 metros de porção de terra, causando em seguida o desabamento das construções existentes". Esse "acidente" fragilizou ainda mais essa área e potencializou o processo erosivo. Os moradores já conviviam há 20 anos com o processo erosivo intenso na vila, no qual o mar comia um metro da ilha por ano: "A erosão provocada pelo Catamarã tomou 20 metros de porção de terra em apenas um dia, encurtando 20 anos de vida do território" ${ }^{\prime 11}$.

Pensar a abertura da barra como um acontecimento que envolveu os fluxos desses ambientes, através do mar, vento e lua, e que foi intensificado pela ação humana, como o Catamarã Maratayama, faz pensar na instabilidade desses lugares e em como se produz meios de viver ali.

Tratam-se de modos de viver se acercando das inconstâncias do mar: o território é terra, mas também é mar, e o mar é fluido, avança sobre áreas de terra que passam a virar mar, e recua deixando a terra aparecer. É um território composto em que a água predomina. Devido a esse movimento, todo o ato de mapear e de saber se orientar, tanto por mato, quanto por mar se complexifica, pois vilas inteiras podem aumentar ou diminuir de tamanho devido à ação das marés ao longo do tempo - além, é claro, do histórico de interferência humana causada por grandes projetos de desenvolvimento ao longo da região do Lagamar e de "acidentes" como o do Catamarã Maratayama. Se movimentar nesses lugares demanda formas de conhecer e de se acercar para lidar com a instabilidade. O movimento é intrínseco às formações territoriais.

Descrever a geografia do Lagamar ajuda a compreender as dinâmicas de movimento do território e das famílias por entre o seu lugar. Abordar esses movimentos é uma maneira de descrever a memória territorial dos sujeitos dessa pesquisa. Essa memória não se pauta apenas pela experiência direta daqueles que viveram em determinado tempo. Ao me contar sobre a história de suas vilas, os moradores mais antigos recorrentemente apontam em direção ao mar para mostrar lugares onde seus pais moravam ou onde eles mesmos moravam quando eram crianças. E era lá que acabava a ilha do Cardoso, de fronte à saída do Ariri, disse Dona Iolanda Pires. Seu Antonio Muniz complementou a fala dela, dizendo que aqui, era como lá, o deserto, o combro ${ }^{12}$. Combro e areia e mato baixo. Ai esse mar aberto lá não vinha na coroa ${ }^{13}$, porque não existia. Vinha aquió. Só que esse aqui era lá, lá na frente, bem prafrente.

Nos momentos em que tive oportunidade de perguntar sobre os movimentos do território para pessoas mais velhas, ouvi interessantes reflexões, como a apontada acima, que me fazem pensar sobre como esses acontecimentos produzem uma memória coletiva, que é experienciada e transmitida ao longo das gerações, e que compõem algo próximo ao que Marques (2015) define como "mapas mnemônicos de socialidade" através de sua pesquisa no sertão pernambucano. A formação das vilas nessa região instável não se deu ao acaso, mas foi uma busca por um lugar que pudesse reunir as condições necessárias para a pesca em mar de fora e mar de dentro, e no qual as famílias pudessem alternar a pesca com os roçados.

11 Informações retiradas de YAMAOKA et al( 2019); e do documento "Ação Civil Pública, com pedido liminar de reparação de danos materiais emergentes" feita pela Defensoria Pública do Estado de São Paulo, através do defensor público Andrew Toshio Hayama em 08/11/2016. Disponível para visualização em: https:/ / racismoambiental.net.br/wp-content/uploads/2016/12/ ACP-NSEADA-DA-BALEIA.pdf. Visualizado em 20/07/2019.

12 Combro é o nome dado para as áreas de restinga que ficam submersas durante a maré alta, elas tem vegetação rasteira.

13 Coroa ou baixio é o nome localmente dado aos bancos de areia, cuja formação no mar se dá pelo acúmulo de sedimentos (areia entre outras coisas). No mar do Ararapira existem várias coroas fixas, mas é importante ressaltar que elas podem se mover ou se desfazer de acordo com o movimento das marés e dos ventos. 
A navegação demanda todo um trabalho de mapear os lugares. Mas não aos moldes convencionais da cartografia. Diria antes que se assemelha mais à ideia de "cartoprática" proposta por Mauro Almeida (2012). Mapear o lugar através da observação e do caminhar, percebendo nuances (imperceptíveis a um "estrangeiro") num ambiente com tonalidades repetidas e num constante mover-se (por água e por terra) é um modo de conhecer e produzir conhecimento em composição com o mundo. O modo caiçara de se movimentar pelo território e, paralelamente, produzir conhecimentos se aproxima da perspectiva teórica de Tim Ingold (2000, 2015), quando o autor afirma que as maneiras de "mover, conhecer e descrever" são facetas paralelas de um mesmo processo de vida. É nas andanças por mar e terra que conhecimentos são experienciados por caiçaras e pescadores artesanais ao longo de seus caminhos de vida. São esses movimentos que produzem constantemente um modo de vida em meio a um território em movimento ${ }^{14}$.

A relação com o mar e o mato em diferentes momentos da vida, e os conhecimentos adquiridos através dessas experiências fazem com que os habitantes das ilhas tenham uma percepção (cf. INGOLD, 2015) muito aguçada sobre os elementos que compõem o seu lugar. Saber reconhecer uma manta (cardume) passando no mar, perceber os contornos da vila durante a variação da maré, saber sobre as safras dos peixes e das frutas, saber movimentar seu corpo junto com o balanço da canoa enquanto rema, entre outros inúmeros exemplos, informam sobre a construção de um corpo a partir de um conjunto de conhecimentos, percepções e habilidades adquiridos que são fundamentais para habitar esse território marítimo e terrestre ${ }^{15}$.

Durante a maré baixa vários baixios e coroas ficam visíveis, e é necessário ter conhecimento para navegar, principalmente em áreas como o Canal do Varadouro e o mar de Ararapira. A maré é um dos fatores ambientais que organiza a vida cotidiana e as atividades de pesca, no sentido em que o seu movimento entre maré alta e maré baixa, ao longo das fases da lua, determinam o uso e o trânsito do e no território. $O$ vento também exerce influência, pois estando a embarcação a favor ou contra a maré, ele pode facilitar ou dificultar a navegação e a pesca - no caso da navegação à vela, por exemplo, o vento exerce maior influência na navegação do que o movimento da maré, embora numa situação de maré e ventos favoráveis as condições de navegação sejam ainda melhores. Ao me ensinar sobre os ciclos dos ventos Dico Muniz disse que eu só conseguiria entender bem se saísse pescar:

\footnotetext{
Pescando que você manja tudo bem certinho o vento. De manhã no barco amanhece aquele vento fria daqui. Vento fria. Quando vai virando pra lá vai esquentando, vento do mar. Aí vira leste, vento bem quente já. Aí de tarde já tá daqui ó, de noite. Quando amanhece ventando torto assim não presta. Se amanhece norte ou nordeste é sinal de que vai virar o tempo pro sul. É, porque de manhã cedo tem que ser vento de terra, daqui pra lá. É tudo feito muito certo demais, é tudo muito certo demais. É igual um relógio, bem certinho. Esse negócio do vento aqui cara é muito tempo que analiso isso aí, e é bem certinho. Quem vive no mar tem que entender bem certinho. Eu aprendi observando né? (Dico Muniz).
}

\footnotetext{
14 Não pretendo neste artigo me deter no modo como os caiçaras se constituem enquanto pessoa, mas a constituição do mundo, através das composições desses habitantes com um território em movimento, é também uma constituição de si, pois através das relações caiçaras com outros seres e elementos que constituem um território entre a terra e o mar, eles estabelecem condições para seu crescimento e desenvolvimento (cf. INGOLD, 2015).

15 Ao descrever e refletir sobre os atributos, relações e experiências que fazem um corpo caiçara, dialogo com a perspectiva de Marisol de La Cadena (2015). Através do conceito de uma "onto-epistemologia" a autora propõe uma reflexão no sentido de que as condições que geram conhecimentos também se desdobram nas qualidades corporais de seus existentes.
} 
Pretendo, portanto, pensar em como essas diferentes temporalidades são compreendidas e como as famílias caiçaras compõem com ela. Como venho argumentando, viver no território é compor com ele e suas adversidades. É lidar com as temporalidades próprias dos não-humanos. Nesse viver observando essas temporalidades e acontecimentos, os caiçaras não se sentem os únicos donos do lugar. Ele é também casa das inúmeras famílias de bichos que com eles compartilham esse mundo e que com eles também compõem. O modo como o joão-de-barro monta a sua casa indica como serão os ventos no inverno; as abelhas no pé de murta indicam que está quase na hora de comer as frutas e plantar as sementes; um pé de mangue crescendo na praia é sinal de que a vila está virando mangue. A observação dessas nuances, a percepção das mudanças diárias, como árvores que caíram, barrancos que desmoronam, bichos que aparecem com maior ou menor frequência: são todos acontecimentos e observações que compõem memórias e práticas territoriais.

\section{Uma memória rápida do lugar: marcar pontos e reconhecer poitadas ou pesqueiros}

O GPS perde pra mim, longe. Eu nasci, bem dizer me criei numa proa de canoa (Seu Cambeva Siqueira, Vila das Peças).

Pescador daqui não usam GPS, sonar, essas coisas. É tudo pelo GPS do próprio indivíduo, da cabeça dele né? (Evair Siqueira, Vila das Peças).

Pra qualquer lugar aqui que você precisa ir, pra pescar, pra cuidar de um roçado, pra andar, você precisa saber o que tem embaixo né? Então a gente mapeia tudo mentalmente, faz uma memória rápida do lugar (Renato Caiçara, Vila das Peças).

Um dia eu tava conversando com um rapaz. Ele:

- Ah, mas eu tenho GPS.

- Isso não adianta você ter GPS.

- Como não adianta?

- Não adianta você ter GPS. Você precisa conhecer primeiro pra depois se usar o GPS, se não não adianta (Seu Rubens Muniz, Barra do Ararapira).

Esses são trechos de narrativas de pescadores em diferentes conversas que tivemos a respeito do uso de aparelhos GPS para navegação. Nenhum deles dispõe de um aparelho desses, mas todos sabem como funciona ou já utilizaram um. Alguns deles acompanham pessoas que praticam pesca amadora com linha e pesca sub (pesca de mergulho com arpão), mostrando alguns pesqueiros ou poitadas, lugares que reúnem condições propícias para a passagem de cardumes. Nessas conversas eles me relataram que os pescadores amadores costumam marcar em seus aparelhos GPS as coordenadas de lugares pelos quais precisam passar sem encalhar suas embarcações em bancos de areia submersos, e também a localização de alguns pesqueiros por eles recomendados.

Perguntei se eles se preocupavam com o fato dessas pessoas terem marcado as coordenadas de alguns de seus lugares de pesca, e as respostas foram negativas. Eles duvidam da precisão dos aparelhos GPS. Seu Rubens rememorou um diálogo que teve com um pesquisador certa vez. Ele dava risada me contando que disse à pessoa que não adiantava ela ter GPS sem conhecer o lugar e as dinâmicas que ali acontecem, pois por mais que o GPS indique pontos específicos, ele não lida bem com a instabilidade. Já Seu Cambeva disse que o GPS perde de longe pra ele, pois nasceu e se criou na proa de uma canoa, e desde muito jovem navegou por entre cada pedaço do mar daquela região: 
Meus pais eu não conheci né? Nem pai e nem mãe, quem me criou foi o meu tio. Então ele era viúvo, então ele saia e fazia uma casa na canoa e minha cama era ali. Eu era pequeno. Ali vinha, tinha pão, tinha tudo pra mim, de café. Ele ia pescar com espinhel, de tarrafa, de godá, pegar camarão (Seu Cambeva).

Nesta sessão descrevo habilidades e percepções de meus interlocutores para se orientar no movimento entre o território marítimo e terrestre, apreendidas por meio da observação e de suas experiências. Como Seu Cambeva, que se criou na proa de uma canoa acompanhando seu tio aprendendo a navegar e a pescar. Como as falas dos pescadores remetem ao uso de aparelhos GPS, inicio apresentando algumas experiências de campo em que tive a oportunidade de entender melhor o seu funcionamento.

Pouco mais de um mês após o rompimento da Ilha do Cardoso, em setembro de 2018, acompanhei um grupo de oceanógrafos do Centro de Estudos do Mar (CEM - UFPR) para realizar a batimetria de alguns pontos do Mar do Ararapira, para calcular a profundidade de um novo canal em formação. Para realizar o trabalho de batimetria, acompanhei a equipe que foi para o mar com um aparelho GPS pequeno e ficamos por algum tempo navegando em ziguezague, para que os devidos aparelhos pudessem medir a profundidade do novo canal em formação cruzando com as coordenadas de localização ${ }^{16}$.

Esses modelos de GPS pequenos (os que utilizamos em carros, celulares e em embarcações pequenas) são utilizados para localização baseados em duas coordenadas, " $x$ " $e$ “ $y$ ". Eles geralmente apresentam erros de precisão que podem chegar até dez metros. A fim de corrigir esses possíveis erros, um dos membros da equipe ficou em uma base fixa, montada em terra, com um aparelho GPS de precisão, que, diferente do modelo pequeno, coleta não apenas coordenadas " $x$ " e " $y$ ", como inclui uma terceira informação, " $z$ ", que mede a altura.

De acordo com os pesquisadores que acompanhei, o uso desses dois equipamentos de medição de coordenadas é necessário, pois a atmosfera nunca é a mesma, e, deste modo, ela interfere nos sinais gerando "erros de precisão". Para corrigir esses erros ocasionados pela influência atmosférica é que se monta uma base com um GPS de precisão em um lugar fixo, num ponto com coordenada e altura já conhecidos e registrados de maneira precisa. Portanto, a coleta de dados através da batimetria, por nós realizada no mar, foi cruzada com as informações de localização do GPS pequeno que estava no barco e com o GPS de precisão que estava no Marujá. Ambos os aparelhos ficaram ligados ao mesmo tempo em uma distância máxima conhecida, coletando os dados com os erros de interferência atmosférica. Como o GPS parado estava supostamente num ponto georreferenciado "conhecido", foi possível filtrar esses "erros atmosféricos" e tirá-los dos dados coletados com o GPS móvel.

A partir dessa experiência eu compreendi melhor o que me disse Seu Cambeva, quando afirma que o GPS perde longe para ele. Ou mesmo quando Seu Rubens diz que é preciso conhecer primeiro, pra depois usar o GPS. O conhecimento cartográfico, de acordo com Mauro Almeida (2012), "uniformiza o mundo em formato, ao mesmo tempo em que estabelece um espaço onde Estados podem agir" (:15). A questão é que a tecnologia utilizada nesses aparelhos tem sua eficiência pautada no método cartesiano que ao digitalizar a geometria permitiu a digitalização do espaço geometrizado (cf. ALMEIDA, 2012). Nesse sentido, as coordenadas marcadas por um GPS nada mais fazem que transformar "a experiência de lugares e de tempos em números" (:17). Essa marcação de coordenadas, via GPS, é um modo de "estriar" o mar, na perspectiva de Deleuze \& Guattari (1997). Por ser um espaço liso, o mar é constantemente tractuzitue transvertido em espaço estriado, segundo os autores ${ }^{17}$.

16 Parte dessas reflexões só foram possíveis através da minha interlocução com Diana Melo Italiani, oceanógrafa que estava conduzindo essa saída de campo e a quem agradeço pela oportunidade de diálogo tão proveitoso.

17 Deleuze \& Guattari trazem questões importantes para pensar o território marítimo . “O espaço liso, háptico e de visão aproximada, caracteriza-se por um primeiro aspecto: a variação contínua de suas orientações, referências e junções opera gradualmente. Por exemplo, o deserto, a estepe, o gelo ou o mar, espaço local de pura conexão" (1997: 181). 
E é por isso que um GPS perde fácil para Seu Cambeva. Um GPS não dá conta das constantes mudanças que estes ambientes estão sujeitos, mesmo àqueles que corrigem erros de precisão. Ainda que se use um aparelho preciso, que um dia você marque pontos de pesca, nada garante que, quando voltar lá, um mês depois, um pesqueiro vai estar no mesmo cruzamento de coordenadas, ou que um banco de areia esteja exatamente no mesmo lugar. Não estamos diante de lugares fixos, mas de lugares que se movem no espaço marítimo. Diferente do GPS, o conhecimento dos pescadores é passível de atualizações a cada dia que eles saem para o mar. Embora suas referências se pautem numa triangulação de pontos em terra, técnica que não se diferencia totalmente do que é utilizado num GPS, a questão é que o conhecimento do pescador é passível de atualizações constantes, de acordo com suas experiências. E justamente pelo fato de que, onde um GPS vê números, um pescador vê o seu lugar em fluxo, composto pelos movimentos de ventos, água, areia, peixes, moluscos, pássaros, gentes, etc.

De acordo com Almeida (2012), as habilidades de mapear não dependem exclusivamente de formação técnica. Pessoas que habitam e mantêm relações de proximidade com determinados lugares, possuem, segundo o autor, uma "ciência do espaço" (ibid.) gravada em seus corpos como uma capacidade de se orientar e se movimentar. Capacidade que é igualmente compartilhada por animais que também habitam esses lugares.

Em suma, a antropologia ensina que todos nós somos receptores de GPS e todos nós utilizamos de SIGs embutidos em nossos corpos e mentes. Há portanto cartopráticas que são ciências populares associadas a múltiplas ontologias, e que não se confundem nem devem ser invisibilizadas pela ontografia universal que implanta cada fragmento da experiência num geóide único. Corpos são GPSs portáteis e embutem SIG tradicionais; mas nada impede que cartografias tradicionais - esses híbridos da experiência espacial com a representação gráfica -- possam canibalizar essas tecnologias a seu serviço, de forma a dialogar com as ontografias universais (ALMEIDA, 2012:16).

Essa capacidade de orientação em determinado lugar, esses "SIGs ${ }^{18}$ embutidos em nossos corpos e mentes", como diz Almeida, lembram a reflexão de Evair, de que os pescadores possuem um GPS do indivíduo, da cabeça dele. É impressionante como os habitantes das ilhas desde criança sabem se localizar, sobre como eles entendem muito sobre o manejo desses ambientes. Andei por vários lugares de Barra do Ararapira acompanhada das crianças, que me mostravam lugares onde antes existiam árvores que gostavam de subir e que naquele momento estavam no chão, derrubadas pela força de maré.

As andanças pelo território, portanto, são orientadas pela constante marcação de pontos. Para andar em terra ou no mar é preciso criar marcas e saber reconhecer pontos. Marcas não visíveis a um observador qualquer, perceptíveis somente por quem tem um conhecimento muito refinado sobre o local. Embora alguns pescadores tenham participado nos últimos anos de projetos de automapeamento, de modo geral a técnica de marcar e reconhecer pontos não é registrada em um mapa convencional, mas no GPS do indivíduo, ficando inscritos na memória dos moradores. O ponto, a marca não estão dados, precisam ser feitos, marcados.

O GPS perde pra Seu Cambeva porque resume um lugar a um conjunto de coordenadas, que indicam a localização de quem está utilizando o aparelho. O GPS não conhece o lugar, nem sua história, diferente dessas pessoas, que ao longo de suas vidas têm acompanhado as mudanças ocorridas no território. Elas sabem informar sobre cada pedaço de mangue que deixou de existir, coberto pelo mar, sabem identificar tudo o que não é visível a um observador de fora, onde existem pedras, sabem identificar profundidade, movimento de cardumes, etc. Portanto, ainda que a tecnologia do GPS indique uma orientação dada por um cruzamento de coordenadas, ele não detém as técnicas utilizadas por caiçaras e pescadores artesanais.

18 Sistemas de Informação Geográfica (SIG) são uma combinação de três tecnologias: sensoriamento remoto (satélites, radares para captação de informações da superfície terrestre); GPS (emite localizações a partir de coordenadas geográficas); e geoprocessamento (tratamento das informações captadas para a produção de mapas).

EntreRios - Revista do PPGANT -UFPI -Teresina • Vol. 2, n. 1 (2019) 
A técnica que orienta os mapeamentos realizados pelos moradores para navegação no mar de dentro é chamada triangulação ${ }^{19}$ de pontos, ou esquadramento de pontos, nomes que variam de pescador para pescador. Essa técnica é utilizada para mapear e futuramente reconhecer pesqueiros (locais em que se pesca com linha e anzol), pontos de pesca (onde se pesca com outros apetrechos, como redes, espinheis, tarrafas etc) e serve também para marcar um ponto qualquer, como, por exemplo, se um morador sai pra pescar e por algum acidente seu barco fica a deriva ou naufraga e ele precisa sair do barco. Para saber voltar no lugar ele precisa marcar o ponto, ou, nas palavras de Renato, criar uma memória rápida do lugar em que o barco foi deixado, mesmo que na volta ele já esteja debaixo d'água.

Marcar e reconhecer pontos demanda conhecer os elementos que constituem determinadas paisagens (cf. INGOLD, 2000). Os pescadores encontram determinadas marcações orientandose por pontos que estão em terra. Pode ser um morro, uma árvore, um farol, uma construção, a ponta de uma ilha. A orientação é dada pela triangulação ou esquadramento, técnica na qual o pescador utiliza referências em terra que estão alinhadas em relação à posição em que ele se encontra. Tal qual a triangulação feita pelo GPS, mas muito mais precisa, pois enquanto aparelhos GPS mais simples admitem erros de precisão que podem variar de centímetros a metros, o pescador consegue ter maior precisão uma vez que os pontos são alinhados em relação a ele. Como me explicou Evair:

É tipo como você esquadra uma casa aqui em terra, a gente faz isso lá no mar, na hora assim a gente faz um esquadro. Faz um mapeamento ali: ah, aqui é o lugar onde eu engato, aqui eu sei que tem peixe porque tem uma pedra, um negócio afundado. E cara, é incrível, você acha certinho o lugar ali. Pode estar força de maré, pode estar longe da praia, tipo lá no meio, você não vê quase nada, e você vê a marca ali. É muito mais preciso que um GPS. Você sabe pelas coisas que tão no continente, liga com o outro lado: aquela montanha, com aquela árvore lá, mais alta, lá no mato. E mantém aquilo ali por um tempo e depois você já, mesmo que suma aquela árvore, você já tem gravado, já sabe o que tem ali(Evair).

Seu Cambeva chama o local indicado pela triangulação de poitada, indicando um pesqueiro localizado em local com correnteza:

\begin{abstract}
Poitada né que a gente chama. Vamo pescar sargo? Então vô lá no arrecife do sargo. Aí tem a pescadinha né, outro peixe. A ponta da vila, pela torre, pela casa do guia. É assim. E tem a redonda, que é um pesqueiro que tem uma pedra do tamanho dessa casa assim redonda. Aí a gente chega e solta, fica numa parte lá e é só jogar e matar peixe. Cada lugar tem um nome. É poitada. Vamos lá na poitada da banana? Banana é lá [indicando com a mão], naquele lugar, lá tem a Poitada da corvina, tem o vedado, tem lá dentro a barranceira, tem, meu senhor, tem tanta coisa (Seu Cambeva).
\end{abstract}

A ponta da vila, pela torre, pela casa do guia, são três pontos em terra que identificam determinado local de pesca. As indicações de localização de alguns pesqueiros fazem referência, através da triangulação, a três ou quatro pontos, nem mais, nem menos que isso. O interessante dessa técnica é que ela serve para criar uma memória rápida. Passado um tempo essa localização já fica registrada na cabeça, ou no GPS do próprio indivíduo. Mesmo que o ponto em terra deixe de existir, o pescador já sabe se localizar. É portanto, muito mais preciso que um GPS, pois enquanto a tecnologia do aparelho estabelece coordenadas, o GPS da cabeça do indivíduo dá o ponto como um lugar em relação a outros lugares: você só vai saber que está naquele ponto quando efetivamente estiver lá, alinhado aos três ou quatro pontos em terra.

19 Há uma vasta bibliografia que aborda esse tema, algumas etnografias que abordam os conhecimentos articulados por pescadores, como as de Sautchuk (2007); Maldonado (1993); e Melo \& Vogel (2004).

EntreRios - Revista do PPGANT -UFPI -Teresina • Vol. 2, n. 1 (2019) 
Esse conhecimento requer uma percepção muito aguçada das nuances do mar, um espaço háptico e liso:

\begin{abstract}
Há uma topologia extraordinariamente fina, que não repousa sobre pontos ou objetos, mas sobre hecceidades, sobre conjuntos de correlações (ventos, ondulações da neve ou da areia, canto da areia ou estalidos do gelo, qualidades tácteis de ambos); é um espaço táctil, ou antes 'háptico', e um espaço sonoro, muito mais que visual... A variabilidade, a polivocidade das direções é um traço essencial dos espaços lisos, do tipo rizoma, e que modifica sua cartografia. O nômade, o espaço nômade, é localizado, não delimitado (cf. DELEUZE \& GUATTARI, 1997: 45).
\end{abstract}

Além desse conhecimento refinado que orienta a navegação, há também os modos de se orientar em terra, no mato ou no mangue. Em terra (mato ou mangue), assim como no mar, todo o ambiente de mata faz parecer que você está no mesmo lugar. Para andar no mato é necessário estar atento aos sons e movimentos, pois como a mata é fechada, a orientação não funciona por triangulação de pontos, sendo realizada em função dos astros (sol ou lua) e das nuances da mata.

Por ser uma tarefa extremamente difícil, aqueles que possuem a destreza de andar no mato, assim como no mar, são comparados a animais que habitam esses lugares e possuem muita agilidade e habilidade em seus movimentos. Como na história que ouvi sobre o mutirão realizado para instalar um encanamento para puxar água do continente, da vila continental até uma vila na Ilha das Peças, na qual um pescador foi alvo dessa comparação:

Eu saio, vou pro mato, saio lá, saio aqui, mas reto assim cara, de 30 quilômetros, você precisa ser uma mega cara engenheiro, conhecer demais, porque o cara fica tonto né? De tanto.. a gente anda tanto no mato que a gente perde a noção as vezes e 30 quilômetros é coisa. É, ele foi uma onça. Andar 30 quilômetros e saber onde você tá, onde tem que sair tudo. Eleé muito bom (Evair).

Ainda que saibam se localizar e se orientar nessas andanças desde muito jovens, não é incomum que pessoas se percam, geralmente no período da noite e em áreas de mata fechada, de onde não se consegue localizar a lua. Já ouvi relatos de moradores mais velhos, que se perderam no mato, como Dona Leontina. Ela foi chamar seu marido que estava trabalhando, mas não o encontrou. Andou, andou, logo começou a escurecer e ela se viu perdida. Leontina parou sua caminhada, pois não fazia sentido andar na mata fechada a noite sem nem ao menos conseguir ver o céu. Ficou no lugar onde estava e quase nem dormiu, pois tinham muitos mosquitos. Precisou esperar o dia amanhecer para se localizar. Depois de passar a noite sendo picada por mosquitos, ela viu onde o sol estava nascendo e prontamente soube voltar para sua casa.

Esses modos de se orientar em terra e no mar por vezes são sintetizados em mapas físicos por algumas pessoas. $\mathrm{O}$ interesse na produção de mapas tem relação com sua participação em projetos de automapeamento e de como essas experiências visam descrever os seus modos de experienciar o espaço (Postigo, 2010). Estes projetos demandam a aprendizagem de técnicas cartográficas através de oficinas que precedem o automapeamento. É interessante pensar como a participação nestes processos fundamenta estratégias de resistência e autonomia sobre o território - trazendo elementos para criar contrapoderes de resistência (Povinelli, 2016).

20 "O projeto Nova Cartografia Social dos povos e comunidades tradicionais do Brasil é pensado por seus idealizadores e pesquisadores/colaboradores como uma "ferramenta" para que novos movimentos sociais lutem pela manutenção de seus territórios através de um processo de 'articulação' e 'resgate' de suas identidades coletivas. O projeto teve como objetivo principal dar condições à autocartografia dos povos e comunidades tradicionais na Amazônia, valorizando os movimentos sociais voltados aos processos de ocupação da região criando condições para um processo de 'territorialização diferenciada'"' (COELHO, 2014: 124).

EntreRios - Revista do PPGANT -UFPI -Teresina • Vol. 2, n. 1 (2019) 
Cito alguns exemplos: entre 2005 e 2007 foi realizado um mapeamento das ilhas do município de Guaraqueçaba através do projeto Cultimar - maricultura, educação ambiental e geração de renda, vinculado a Universidade Federal do Paraná com a publicação do “Mapa de Uso Caiçara"; no ano de 2010 foi realizada a primeira cartografia social em território caiçara, que culminou na publicação: "Nova Cartografia social dos povos e comunidades tradicionais do Brasil: Pescadores artesanais da Vila de Superagui, município de Guaraqueçaba, Paraná", através da articulação com o Projeto Nova Cartografia Social da Amazônia; e, recentemente, entre 2014 e 2015, o Movimento dos Pescadores e Pescadoras Artesanais do Litoral do Paraná (MOPEAR) produziu 10 mapas de Autodemarcação do Território Tradicional, com o apoio do Grupo de Pesquisa Identidades Coletivas, Conflitos Territoriais e Educação Emancipatória no Sul do Brasil.

Como o caso de Renato, que depois de participar na elaboração do "Mapa de uso caiçara" nunca mais deixou de fazê-los. Chamou-me a atenção um projeto que ele está começando a desenvolver por conta própria, um mapa de ocorrência de aves. Ele anda sempre com um caderno de anotações e cada vez que vê um pássaro anota o ponto em que o viu e o seu nome. Seu objetivo é que ao longo do tempo consiga ter informações mais precisas sobre espécies e rotas dos pássaros da região. De acordo com Renato, tudo é mapeável, inclusive a rota de alguns pássaros:"

\begin{abstract}
Tem muitas informações que podem ser colocadas dentro de uma mapa como esse. A rota do papagaio [papagaio-da-cara-roxa, espécie endêmica na região], por exemplo, é fácil, eles têm rota fixa, não saem voando por aí sem destino. São duas rotas e dois grupos. Um deles saem daquela ilhota, ao longo do dia vem pra cá e no fim da tarde se recolhem na Ilha do Mel. Na outra eles saem de Superagui [ilha do Superagui], durante a tarde também passam aqui e no fim da tarde se recolhem também na ilhota. Essas são duas rotas que eu sei, podem também ter outras várias rotas (Renato).
\end{abstract}

Os pássaros não se movimentam a vida toda seguindo uma mesma rota e os caiçaras sabem disso. Numa tarde na casa de Renato e Andressa, enquanto olhávamos um mapa desenhado por ele há mais de dez anos, ele foi me descrevendo cada detalhe da baía, o canal de maior profundidade por onde passam os navios que chegam ao porto de Paranaguá, contou sobre a localização de alguns sambaquis, além de contar detalhes da ocupação sambaquiba na região. Ao me descrever o que significava cada legenda do mapa, Renato foi me falando sobre as mudanças do território ao longo do tempo:

\footnotetext{
Quando o sambaquiba morou aqui, há dez mil anos atrás, as ilhas, essa parte verde [do mapa], vinha aqui, tanto que a gente encontra um monte de sambaqui marinho, que tá na água agora, porque, porque a terra recuou. Quando o sambaquiba morava aqui na vila não tinha floresta em cima do banco de areia. A ilha era o banco de areia, por isso que ele fazia uma monte de concha pra poder ficar em terra seca (Renato).
}

Renato acumula muitos conhecimentos sobre as mudanças no território e já produziu muitos mapas. Um deles é esse mapa em que mostra locais de naufrágio, pesqueiros e poitadas, construções antigas, localização de vilas. Nesse mapa, que abrange parte do município de Paranaguá e todo o município de Guaraqueçaba, Renato desenhou 190 legendas e as localizou ao longo do mapa. Segundo ele, o mapa ainda não está pronto.

Pode ver, como geralmente eu faço mapas pensando em identificar coisas no mar, o mar sempre fica numa escala maior. Nesse mapa eu quis mostrar mais o que tem na terra, nos matos. Isso ainda foi pouco mapeado por aqui e olha, tem coisa pra caramba, não tem quase nada aqui (Renato). 
Diferente dos mapas cartográficos, os mapas de Renato são sensíveis às mudanças e aos movimentos do território. Sua relação com os mapas, remete às relações dos Potiguaras com mapas, descrito por Cardoso et al (2017) em artigo sobre o processo de etnomapeamento. Para os autores a relação de seus interlocutores com mapas poderiam ser compreendidas "como a de territorialidades em movimento com um cerne que se revigora, com práticas que se mantêm e que, ao mesmo tempo, incorporam outras estratégias" (:84).

\section{Algumas considerações finais: composições políticas, resistências e conhecimentos}

As narrativas das pescadoras e pescadores a respeito do uso de aparelhos GPS para navegação me inspiraram a pensar sobre o que os faz serem considerados de modo geral, mais limitados. Através da descrição das técnicas, habilidades e percepções desses sujeitos e da maneira como articulam seus conhecimentos para navegar e se orientar no mar e na terra, por entre territórios em movimento, é possível entender a limitação do GPS por eles apontada. O GPS perde pros pescadores porque o aparelho não detém técnicas para lidar com a instabilidade, porque ele não reconhece lugares. Se acercar e aprender a lidar com a instabilidade são modos de compor com as adversidades, resistind o e adaptando-se a elas de maneira criativa.

O método cartográfico convencional, ao codificar a experiência (cf. ALMEIDA, 2012) e delimitar localizações a partir de coordenadas geográficas, não marca os lugares que compõem os territórios caiçaras. Esses modos de se movimentar e se orientar através da memória rápida e da marcação ou triangulação de pontos não se resumem a coordenadas geográficas. Criar uma memória rápida, como disse Renato, requer um pertencimento e a articulação de conhecimentos que perpassam relações entre humanos e não humanos em seus encontros e percursos, pautados por uma experiência territorial muito bem localizada.

Ao longo desse texto abordei processos e relações que devem ser lidos como políticos. A articulação de conhecimentos que devem ser o tempo todo atualizados, o modo como se passam ou não informações a quem é de fora, as contradições da política ambiental brasileira, a resistência visualizada através da composição com a instabilidade territorial, as políticas de estar no mundo: são modos políticos de composição, de feitura do território. Esses processos indicam políticas de vida, de estar no mundo, a criação de possibilidades de existência.

Ao descrever os conhecimentos e composições caiçaras é preciso não separar essas relações (locais) de um contexto mais amplo. O modo de articular e narrar seus conhecimentos e práticas é também mediado por um contexto conflituoso relativo às interdições ambientais, aos projetos portuários, turísticos e à pesca industrial.

Essas adversidades dadas pelos movimentos do mar e da terra são atravessadas o tempo todo por relações políticas mais amplas: as contradições da política ambiental brasileira através das Unidades de Conservação, que interditam caiçaras e pescadores artesanais criminalizando suas práticas; o modo como o Estado formula leis ambientais sem levar em consideração o que dizem os habitantes dessas regiões; e o modo como criminaliza povos tradicionais ao mesmo tempo em que permite a construção e a ampliação de projetos de desenvolvimento a poucos quilômetros de distância desses locais por ele denominados como "santuários e berçários naturais da Mata Atlântica". A contradição da política ambiental brasileira reside nesses processos unilaterais, totalmente desfavoráveis à "conservação" queé seu objetivo.

Um território movente, feito de relações, percursos e acontecimentos, assim como o espaço nômade, pode ser localizado, mas não delimitado (cf. DELEUZE E GUATTARI, 1997: 45). Caiçaras e pescadores artesanais se movem por entre lugares e não num espaço abstrato. Esses lugares são marcados por suas experiências, suas histórias de vida, suas memórias, acontecimentos geológicos e cosmológicos. É por isso que um GPS perde pra Seu Cambeva, como perde para todos eles. As práticas e habilidades caiçaras não podem ser apreendidas e codificadas apenas como coordenadas geográficas. Em um contexto de inúmeras violações de seus direitos, ganhar do GPSé um modo de manter a autonomia sobre seus territórios. 


\section{Referências Bibliográficas}

ALMEIDA, M. W. B. Outros Mapas (Conferência de Encerramento-INJPS). 2012.

. “Caipora e Outros Conflitos Ontológicos". R@U : Revista de Antropologia Social dos Alunos do PPGAS-UFSCAR, v. 5, p. 7-28, 2013.

BRASIL. "Lei no 9.985 de 18 de julho de 2000. Institui o Sistema Nacional de Unidades de Conservação SNUC". Diário Oficial da União, Brasília, DF, 19 jul. 2000. Seção1.

CARDOSO, T. M.; PARRA, L. B.; MODERCIN, I. F. “Mapas em movimento: os (des)caminhos de uma prática cartográfica junto aos potiguara". Espaço Ameríndio (UFRGS) , v.11, p. 71-111, 2017.

COELHO, K. Entre ilhas e comunidades: articulações politicas e conflitos socioambientais no Parque Nacional do Superagui. Dissertação de Mestrado. Departamento de Antropologia, Universidade Federal do Paraná, 2014.

“Entre a terra e o mar: notas sobre o direito costumeiro e a divisão do território entre famílias caiçaras do litoral norte paranaense". In: Dossiê Pesca: Populações ribeirinhas e costeiras. Vivência: revista de antropologia. UFRN/DAN/PPGAS v. I., N 47 (jan/jun. De 2016) - Natal: UFRN. 2016.

DELEUZE, G. \& GUATARRI, F. “Rizoma”. In: Mil Platôs: capitalismo e esquizofrenia. Vol. 1. São Paulo: Editora 34, 1997.

. "Tratado de nomadologia: A máquina de guerra". In: Mil Platôs: capitalismo e esquizofrenia. Vol.5. São Paulo: Editora 34, 1997.

$34,1997$.

“O liso e o estriado". In: Mil Platôs: capitalismo e esquizofrenia. Vol. 5. São Paulo: Editora

INGOLD, T. The perception of the environment: essays on livelihood, dwelling and skill. London and New York: Routledge, 2000.

"A antropologia ganha vida". In: Estar vivo: ensaios sobre movimento, conhecimento $e$ descrição. Petrópolis, RJ: Vozes, 2015.

MALDONADO, S. Mestres E Mares: espaço e indivisão na pesca marítima. São Paulo; Annablume, 1993.

MARQUES, A.C. “Fundadores, Ancestrais e Inimigos”. In: Percurso e Destino. Parentesco e família no sertão de Pernambuco e Médio-Norte do Mato Grosso. Tese de Livre-Docência. Departamento de Antropologia, Universidade de São Paulo, pp. 180-203, 2015.

MELLO, M. e VOGEL, A. Gente das areias: história, meio ambiente e sociedade no litoral brasileiro. Maricá, RJ - 1975 a 1995. Niterói; EdUFF, 2004. 
Nova cartografi a social dos povos e comunidades tradicionais do Brasil: Pescadores Artesanais da Vila de Superagui, município de Guaraqueçaba, Paraná / Alfredo Wagner Berno de Almeida, Rosa Acevedo Marin, (Coord) ; autores Roberto Martins de Souza, Dimas Gusso. Guaraqueçaba, Paraná :Projeto Nova Cartografi a Social da Amazônia / UEA Edições, 2010.

NOGUEIRA, P. R.. “Caiçaras lutam contra 'expulsão pelo cansaço' de Estação Ecológica da Juréia (SP)" . Jornal Brasil de Fato, São Paulo, 24 jun. 2019.

POSTIGO, A. A terra vista do alto: usos e percepções acerca do espaço entre os moradores do Rio Bagé, Acre. Tese de Doutorado. PPGAS, Instituto de Filosofia e Ciências Humanas. Universidade Estadual de Campinas, 2010.

POVINELLI, E. Geontologies: A requiem to late liberalism. Durham, London: Duke University Press, 2016.

SAUTCHUK, C. O arpão e o anzol: técnica e pessoa no estuário do Amazonas (Vila Sucuriju, Amapá). 2007. Tese (Doutorado em Antropologia Social)-Instituto de Ciências Sociais, Universidade de Brasília, Brasília, 2007.

VIEIRA, S.A. Resistência e Pirraça na Malhada. Cosmopoliticas Quilombolas no Alto Sertão de Caetité. Tese de Doutorado. PPGAS, Universidade Federal do Rio de Janeiro/Museu Nacional, 2015.

“Micropolítica da pirraça, ou por que resistência não é uma noção obsoleta". Revista Fevereiro, jan. 2018.

YAMAOKA, J.G. et al. “A comunidade caiçara da Enseada da Baleia e a sua luta pelo território -Cananéia (SP)”. Guaju, Matinhos, v.5, n.1, jan./jun. 2019. 